\title{
Relationships between Imperfections and Shear Buckling Resistance in Web Plate with Sectional Damage Caused by Corrosion
}

\author{
Jin-Hee Ahn, ${ }^{1}$ Shigenobu Kainuma, ${ }^{2}$ Won-Hong Lee, ${ }^{1}$ Youn-Ju Jeong, ${ }^{3}$ and In-Tae Kim ${ }^{4}$ \\ ${ }^{1}$ Department of Civil Engineering, Gyeongnam National University of Science and Technology, \\ Jinju, Gyeongnam 660-758, Republic of Korea \\ ${ }^{2}$ Department of Civil Engineering, Kyushu University, Fukuoka 819-0395, Japan \\ ${ }^{3}$ Structural Engineering Research Institute, Korea Institute of Civil Engineering and Building Technology, \\ Goyang, Gyeonggi 411-712, Republic of Korea \\ ${ }^{4}$ Department of Civil Engineering, Pusan National University, Pusan 609-735, Republic of Korea \\ Correspondence should be addressed to In-Tae Kim; itkim@pusan.ac.kr
}

Received 10 May 2016; Accepted 16 June 2016

Academic Editor: Guillermo Rus

Copyright @ 2016 Jin-Hee Ahn et al. This is an open access article distributed under the Creative Commons Attribution License, which permits unrestricted use, distribution, and reproduction in any medium, provided the original work is properly cited.

\begin{abstract}
This study deals with the relationship between imperfections and shear buckling resistance of web plates with sectional damage caused by corrosion. To examine the imperfection effect on the shear buckling resistance of a web plate with sectional damage, a series of nonlinear finite element (FE) analyses were carried out for a web plate with sectional damage, which was assumed as local corrosion damage. For considering imperfections of the web plate in the girder, initial out-of-plane deformation was introduced in the FE analysis model. Using the FE analysis results, the changes in the shear buckling resistance of the web plate with sectional damage were quantitatively examined and summarized according to the aspect ratio, boundary conditions, and height of the damaged section of the web plate. The effects of web imperfections on the shear buckling resistance were evaluated to be little compared to that of the web plate without sectional damage. The shear buckling resistance was shown to significantly change in the high-aspect-ratio web plate. A simple evaluation equation for the shear buckling resistance of a web plate with sectional damage was modified for use in the practical maintenance of a web plate in corrosive environments.
\end{abstract}

\section{Introduction}

For steel girder bridges, the structural member at the end girder near the support can be easily exposed to rain water, high humidity, and wet depositions, which are causes of atmospheric corrosion. Thus, research related to corrosion problems, focused on end girders, has been conducted to determine the residual strength and behaviors of corroded end girders to improve their strengthening methods and maintenance. For the end girder part, the lower region of the web panel, the stiffener on the bearing, and the lower flange on the sole plate have been considered to be the regions vulnerable to corrosion due to their atmospheric corrosion environment, which consists of high humidity caused by poor air circulation, sediments, and rainwater (antifreeze) [15]. Corroded lower flanges in end girders have a relatively smaller effect on the flexible resistance of a girder due to their structural behaviors under applied moment conditions. Therefore, the lower region of a web panel and a stiffener on a bearing are the main components that should be examined for residual strength or local structural behaviors when conducting research on corrosion problems focused on end girders. A lot of research on the structural behaviors of web panels with lower regional sectional damage has been carried out to examine the shear buckling resistance and shear buckling behaviors [1-12]. Many researches were conducted in Japan, where there are severe corrosion environments and many old structures $[2,4,10,11]$. The research mainly dealt with 
the shear buckling resistance and behaviors of web panels using experimental and numerical methods [3-5]. The shear buckling strength of a web panel is affected by the geometrical properties of the web panel. Imperfections and residual stress also affect its shear buckling strength. However, most of the previously conducted research deals with the corroded area and level of web plate as the main parameters affecting shear buckling resistance [3-6]. Imperfections such as eccentric deformation and residual stress were partially considered [13, 14]. Therefore, they were not evaluated to examine the change in their effect on shear buckling resistance. The residual stress of a web panel cannot be clearly determined until after its long service period. In contrast, the eccentric deformation of a web plate can occur during its service period. Therefore, the imperfection effect of eccentric deformation on the shear buckling strength can be considered to determine the lower boundary of the shear buckling resistance of a web panel with local sectional damage caused by corrosion. In this study, therefore, the imperfection effects of eccentric deformation on the shear strengths of web panels with local sectional damage were examined using finite element (FE) analysis. An allowable imperfection level suggested by the design guidelines for the steel structure was considered to identify the shear buckling behaviors of web panels. After identifying a shear buckling analysis model incorporating imperfections, parametric studies were conducted to quantitatively evaluate the shear buckling strengths and the modified shear buckling reduction factor for the damaged web section with imperfections.

\section{FE Analysis Model of Sectional Damaged Web Plate with Imperfections}

In previous studies, Kim et al. conducted a shear loading test of a web plate with artificial sectional damage to experimentally examine the shear buckling resistant behaviors [3]. FE analyses on shear buckling behaviors of a sectional damaged web plate caused by corrosion were conducted to suggest changes in the residual shear buckling strength based on geometrical properties of the web and corrosion level [4]. The shear buckling failure mode of the web plate was also examined considering the corrosion pattern [5]. In previous studies, however, imperfection effect as eccentric deformation was not considered in suggesting its residual shear bucking strength. In this study, an FE analysis model including imperfections was made based on previous models $[3,4]$.

2.1. Geometrical Properties of Web Plates. In this study, imperfection was considered as a main parameter. Eccentric deformation of the web plate was considered as the initial imperfection. Thus, three different initial imperfection magnitudes of $H / 100,000, H / 500$, and $H / 100$ were used to examine the imperfections of the web panel, where $H$ is the web height of the web panels. An arbitrary small initial imperfection level of $H / 100,000$ was incorporated in an attempt to find a bifurcation-type buckling load. $H / 100$ is the maximum imperfection level allowed by the Bridge Welding Code [15], and $H / 500$ is an intermediate level between the two values. For web plate models, a two-web-panel plate girder was selected that had a height of $800 \mathrm{~mm}$, a flange width of $200 \mathrm{~mm}$, a flange thickness of $16 \mathrm{~mm}$, and a web thickness of $6 \mathrm{~mm}$. These dimensions are similar to previous studies [3]. Figure 1 shows the basic dimensions of the FE analysis model.

For the sectional area damaged by corrosion, a damaged area was selected from the lower flange to $100 \mathrm{~mm}$ and $200 \mathrm{~mm}$, as shown in Figure 1. For the selected corroded area, web thickness was decreased from the design thickness for both of the web plates. To consider the aspect ratio of the web plate and the boundary conditions based on the deterioration of the support (bearing) due to corrosion and depositions around the support, the aspect ratios were also changed to 1.0, 1.25 , and 1.50 , and their boundary conditions were changed from a simply supported case to a hinge-supported case.

The following describe the numerical parameters in this study:

(1) Imperfection levels (initial eccentric deformation): 0, $H / 100, H / 500$, and $H / 100,000$.

(2) Sectional damaged web height $\left(h_{c}\right): 100 \mathrm{~mm}$ to $200 \mathrm{~mm}$ from the lower flange.

(3) Web plate thickness $\left(h_{c}\right)$ : changed to $1 \mathrm{~mm}$ from the design thickness.

(4) Web plate aspect ratio $\left(l_{w} / h_{c}\right): 1.0,1.25$, and 1.50 .

(5) Boundary condition: simply supported model and hinge-supported model (with deterioration of support).

2.2. FE Analysis Model. To numerically examine the shear buckling strength of web panels, eigenvalue and incremental nonlinear analyses were conducted. MARC Mentat 2010 was used as the numerical FE program and the web plate model was constructed using a four-node shell element with a $10 \mathrm{~mm}$ mesh size, as shown in Figure 2 [16]. The web plate model was assumed to exhibit elastic, perfectly plastic behavior, and the von Mises yield criterion was used for material plasticity. An incremental load was applied at the center span of the upper flange. Its material was determined to have Young's Modulus of $206,000 \mathrm{MPa}$, a nominal yield stress of $359 \mathrm{MPa}$, and Poisson's ratio of 0.3 [3]. To consider the imperfection effect in the FE analysis model, artificial eccentric deformation was applied to the center of the web plate girder model according to each imperfection level. For the previously mentioned boundary condition cases of the FE analysis models, the left and right supports were changed to hinges or rollers, depending on the supported conditions, as shown in Table 1. Lateral translations and rotations of both supports were restricted, and longitudinal translation of the center of the lower flange was also restricted.

2.3. FE Model Comparison. To validate the FE analysis model, an FE analysis model of the shear loading test specimen in the previous study $[3,4]$ was also constructed for comparison with the FE analysis results from this study. In cases of shear loading tests, out-of-plane deformation can be a major 
TABLE 1: Boundary conditions.

\begin{tabular}{|c|c|c|c|c|c|c|c|}
\hline Boundary condition & Boundary & $u_{x}$ & $u_{y}$ & $u_{z}$ & $r_{x}$ & $r_{y}$ & $r_{z}$ \\
\hline \multirow{3}{*}{ Simple support } & Boundary A & Movable & Fixed & Fixed & Fixed & Fixed & Movable \\
\hline & Boundary B & Movable & Fixed & Fixed & Fixed & Fixed & Movable \\
\hline & Boundary C & Fixed & Movable & Movable & Movable & Movable & Movable \\
\hline \multirow{3}{*}{ Hinge support } & Boundary A & Fixed & Fixed & Fixed & Fixed & Fixed & Movable \\
\hline & Boundary B & Fixed & Fixed & Fixed & Fixed & Fixed & Movable \\
\hline & Boundary C & Movable & Movable & Movable & Movable & Movable & Movable \\
\hline
\end{tabular}

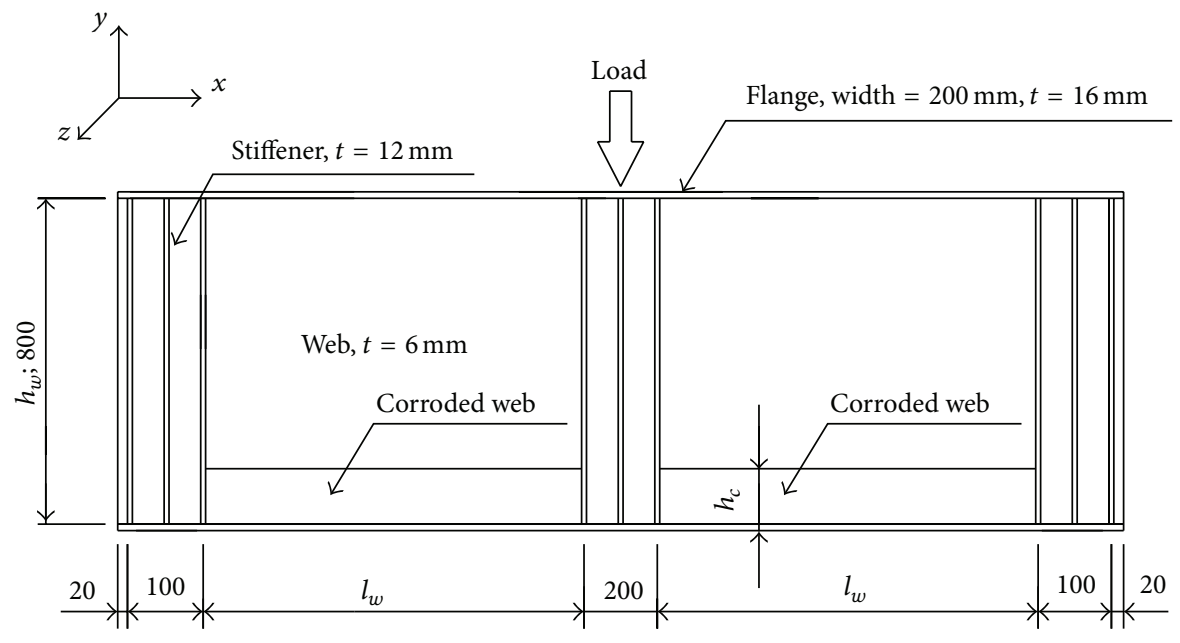

FIGURE 1: Dimensions of FE analysis model (unit: mm).

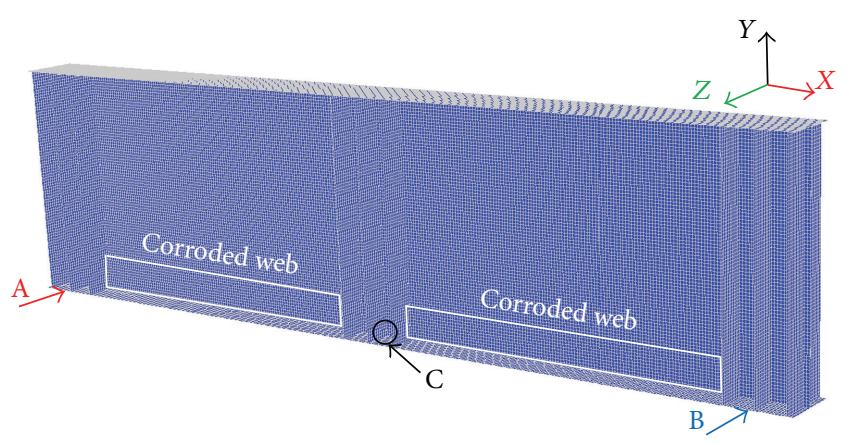

FIGURE 2: FE analysis model.

concern in shear buckling behaviors of web panels. Thus, outof-plane displacements of each test specimen were directly compared with those of the constructed FE analysis model. In previous shear loading tests and analysis studies, corrosion conditions were considered as a main parameter and initial eccentric deformations were not identified. Therefore, initial imperfection effects were not considered in previous studies $[3,4]$. In the validation model, three initial eccentric deformations of the web plate were considered as imperfections, and both supports were considered as hinge supports, like the support conditions of previous shear loading tests $[3,4]$.

Figure 3 shows the out-of-plane displacement comparison at the web center between the shear buckling test results and the FE analysis results under varying initial eccentric deformations (imperfection magnitudes) of the web panel. As shown in the figure, if there is no initial imperfection in the web panel, out-of-plane displacement does not occur before elastic shear buckling of the web panel. After elastic shear buckling of the web panel, out-of-plane displacement appears laterally in the $\mathrm{FE}$ analysis results without initial imperfections, as in the previous study [4]. In the results of the shear loading test specimens [3], their out-of-plane displacements could be directly found without the lateral resistance of the web plate after applying shear load to all test specimens. Table 2 and Figure 4 summarized the comparison of shear buckling strengths of test specimens and FE analysis results. For the Ch00T6 specimen without sectional damage, its outof-plane displacement behavior shows that it is similar to that of the analysis model, excluding the $H / 100,000$ cases, in that the test results were similar to the analysis model as initial imperfection magnitude increased. For the $H / 500$ case, the tendency toward out-of-plane displacements was shown to be in agreement with those of the test results. The shear buckling strength of FE analysis result was also shown to be close to those of the test results for $H / 100$, although it was stiffer than the other cases in the Ch00T6 specimen. Thus, the initial eccentric deformation of the Ch00T6 specimen could be thought to be about $1.6 \mathrm{~mm}$. Other specimens with sectional damage also showed similar results to the analysis results of the Ch00T6 specimen. They also had about $1.6 \mathrm{~mm}$ of initial eccentric deformations (imperfection magnitudes). Their shear buckling strength test results were 


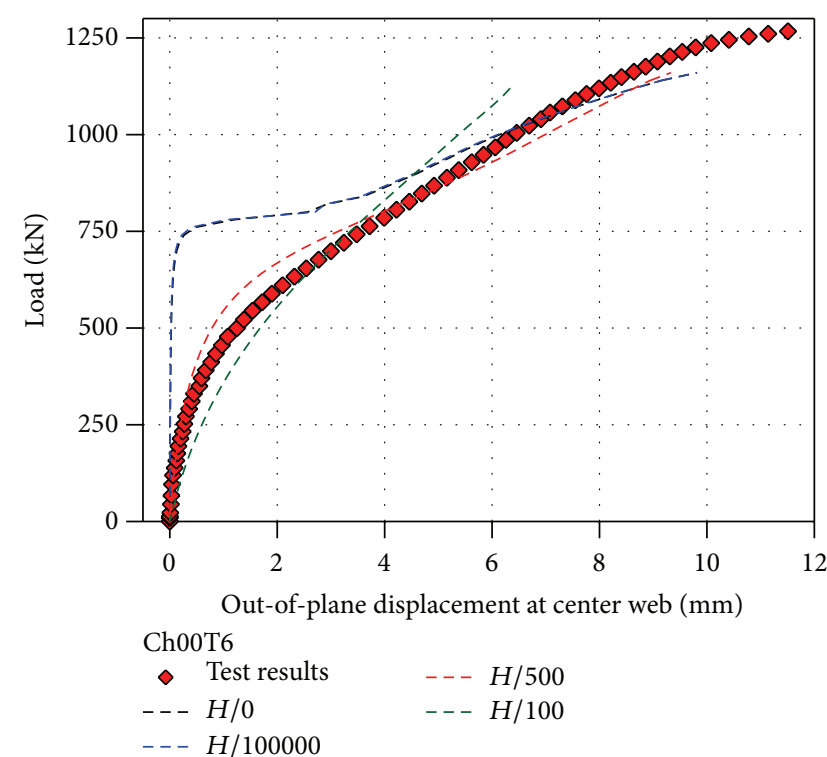

(a) Ch00T6 specimen

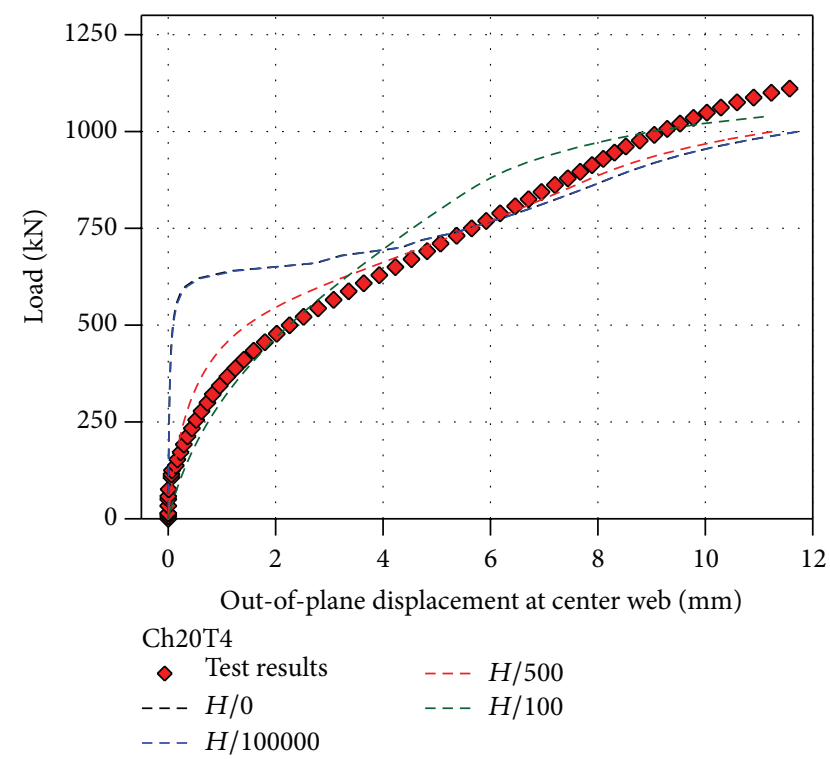

(c) Ch20T4 specimen

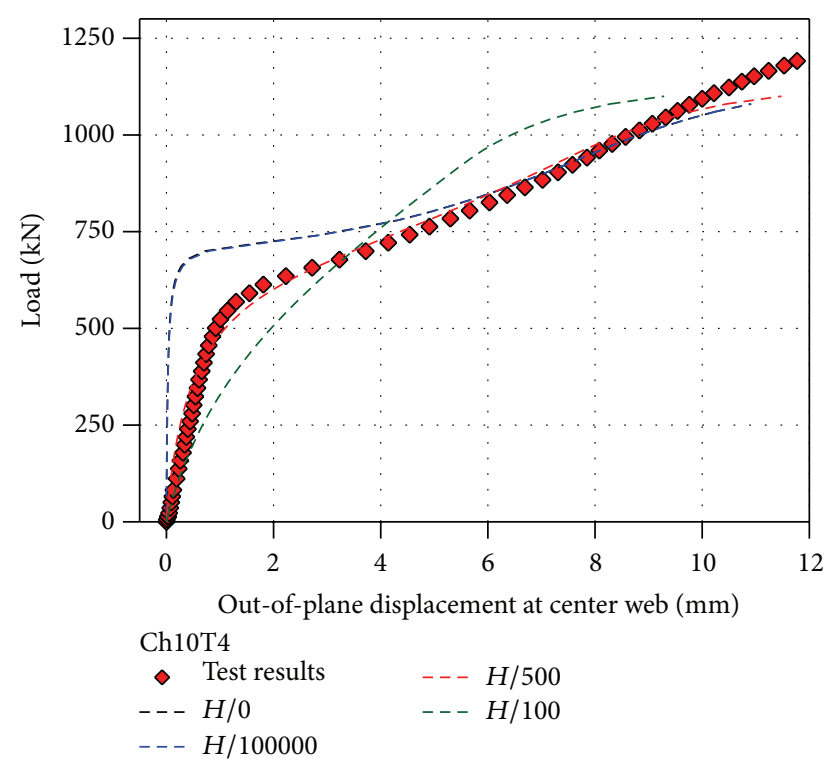

(b) Ch10T4 specimen

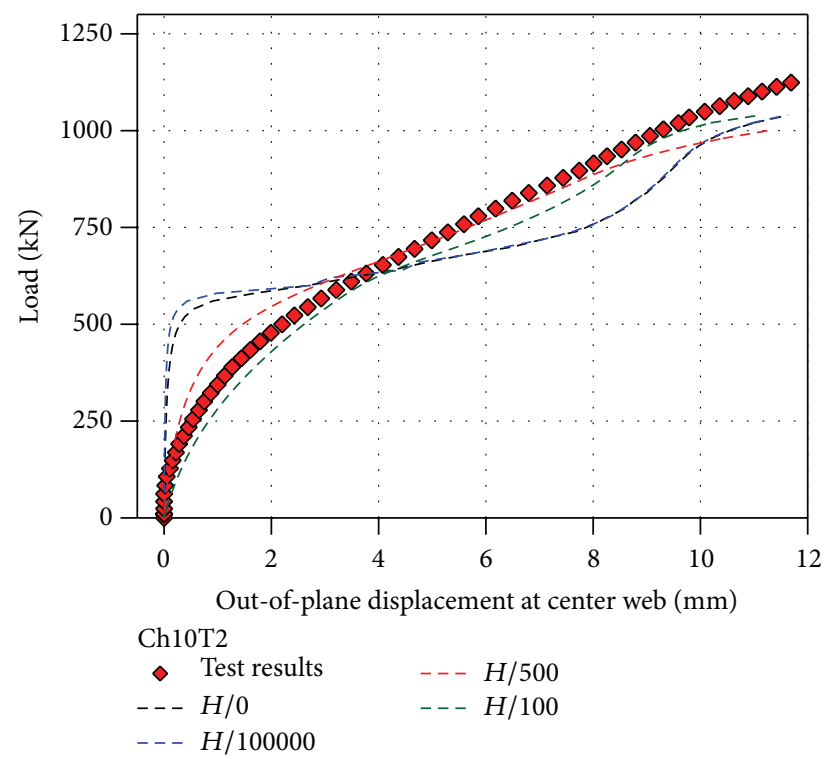

(d) Ch10T2 specimen

FIGURE 3: Out-of-plane displacement comparisons at center web of shear buckling test specimens.

approximately $110 \%$ of the FE analysis results. From the FE analysis results, their shear buckling strengths were shown to slightly decrease, depending on the increase in the initial eccentric deformations.

For the shear loading test specimens, typical shear failures of the webs with a tension field band were shown from the shear resistant behavior of the web, as shown in Figure 5(i) [3]. In particular, for the specimen with sectional damage, the tension field bands were larger and extended into the sectional damaged web plate. An additional pronounced shear-bending tension field occurred in the sectional damaged web [3]. To evaluate the differences between the shear failure modes of the web plate with sectional damage more clearly, the failure modes were also compared according to their initial eccentric deformation. Since the out-of-plane displacements of the $H / 500$ and $H / 100$ cases were shown to be similar to the test results, the representative shear failure modes of the test results were compared with those of the FE analysis, as shown in Figure 5. Their comparison showed a typical diagonal tension field, as well as a pronounced shear tension field in the sectional damaged web plate regardless of their initial eccentric deformation levels, although the point of the maximum out-of-plane displacement slightly decreased. This is shown in Figure 5.

By comparing their out-of-plane displacement behavior, the FE analysis model with initial eccentric deformation was considered to well simulate the shear buckling behaviors of a web plate with an initial imperfection. An initial eccentric 
TABLE 2: Shear buckling strengths of test specimens and FE analysis results.

\begin{tabular}{|c|c|c|c|c|c|c|c|c|}
\hline & \multirow{2}{*}{ Corroded height $(\mathrm{mm})$} & \multirow{2}{*}{ Corroded thickness (mm) } & \multirow{2}{*}{ Corroded volume ratio (\%) } & \multicolumn{5}{|c|}{ Shear buckling strength $\left(P_{u}\right), \mathrm{kN}$} \\
\hline & & & & Tests & $H / 0$ & $H / 10000$ & $H / 500$ & $H / 100$ \\
\hline Ch00T6 & 00 & $0 / 00$ & 00 & 1286.54 & 1160.0 & 1160.0 & 1160.0 & 1140.0 \\
\hline Ch10T4 & 100 & 2 & 4.17 & 1275.75 & 1120.0 & 1120.0 & 1120.0 & 1100.0 \\
\hline Ch20T4 & 200 & 2 & 8.33 & 1152.46 & 1080.0 & 1080.0 & 1080.0 & 1060.0 \\
\hline Ch10T2 & 100 & 4 & 8.33 & 1186.37 & 1060.0 & 1060.0 & 1060.0 & 1040.0 \\
\hline
\end{tabular}

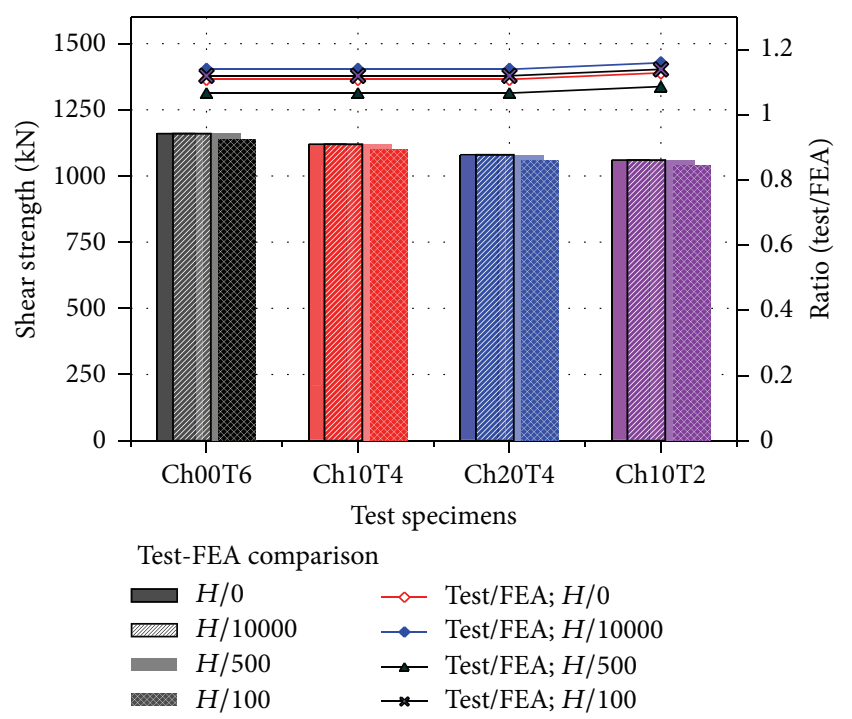

FIgURE 4: Comparison of test and FE analysis results.

deformation of the web plate could slightly affect the shear buckling strength. Therefore, the FE analysis model and FE analysis parameters are suitable for evaluating the shear buckling strength of a web plate with initial eccentric deformations and for examining the relationship between imperfections and shear buckling strength of a web plate with sectional damage.

\section{Discussion of FE Analysis Results}

\subsection{Shear Buckling Resistance Depending on Imperfection}

3.1.1. Relationship between Imperfection and Corrosion Height. Imperfection effects on shear buckling strengths of a web plate with sectional damage caused by corrosion were compared using an FE analysis model and shear loading test results. Three different initial eccentric deformations of $H / 100,000, H / 500$, and $H / 100$ in an $800 \times 1200 \mathrm{~mm}$ web plate were compared for simple supported conditions. As their shear buckling behaviors were shown to be similar according to test results and model comparisons, the change in the shear bucking strength was examined based on the initial eccentric deformations of the web at each damaged web height (100 $\mathrm{mm}$ and $200 \mathrm{~mm})$. Table 3 summarizes the shear buckling strengths of web panels with sectional damage based on their imperfection conditions. Using the data from Table 3, Figure 6 shows the change in the shear buckling strengths of a web plate with imperfections with varying damaged web thickness and corrosion volume. In web panels with a $100 \mathrm{~mm}$ sectional damaged web plate, the shear buckling strengths without imperfection changed from 1160.0 to $959.9 \mathrm{kN}$, and the shear buckling strengths with an $H / 00$ eccentric deformation changed from 1140.0 to $940.0 \mathrm{kN}$. In web panels with a $200 \mathrm{~mm}$ sectional damaged web plate, the strengths without imperfection changed from 1160.0 to $779.9 \mathrm{kN}$, and the strengths with an $\mathrm{H} / 00$ eccentric deformation changed from 1140.0 to $779.9 \mathrm{kN}$. These results showed that the height of the sectional damaged web plate affected the decrease in the shear buckling strengths of web panels from $17.54 \%$ to $32.77 \%$ due to the decreased shear resistance of the web plate, as shown in Table 3 and Figure 6. These results were similar to the decrease in the shear buckling strengths of web panels with increasing sectional damaged web plate thickness and height found in the previous study [4]. For $H / 100,000$ and $H / 500$ eccentric deformations of web panels, their effects were shown to be similar to those of the web plate without eccentric deformation, as shown in the out-of-plane displacement relationship comparisons of the shear loading test in Figure 3 and Table 2. In particular, in the case of $H / 100$, its values decreased slightly more than in the other cases, and its values were evaluated to be $2 \%$ of the values of the web plate without eccentric deformation. Thus, it was determined that the effect of the initial eccentric deformation of a web plate is relatively less than that of the sectional damaged web plate.

3.1.2. Relationship between Imperfections and Boundary Conditions. In the previous study [4], the critical shear buckling value of a web plate was affected by the boundary conditions, and shear buckling resistance was steadily decreased according to sectional damage related to web corrosion. The boundary conditions had very little effect on shear buckling strengths [4]. In this study, the effect of initial eccentric deformation on shear strength was also examined to determine the relationship between shear strength and boundary condition. The same initial eccentric deformations and sectional damaged height conditions as the imperfection model cases were applied to the FE analysis model, and the model boundary conditions were only changed by incorporating a hinge considered to be a deteriorated boundary. Table 4 and Figure 7 summarize the shear buckling strengths of a web plate with sectional damage based on their imperfection and boundary conditions. With regard to the imperfection levels, the shear buckling strengths were evaluated to be similar to values of the simply supported condition regardless of 


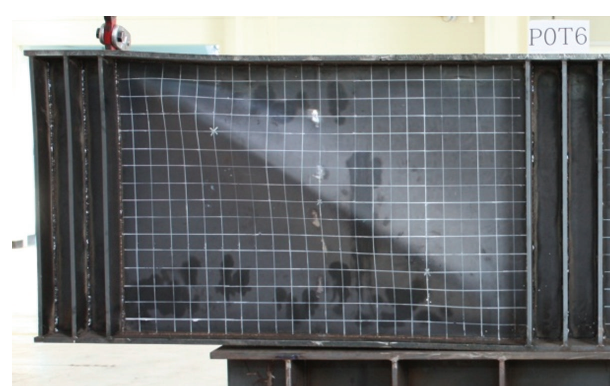

(i) Failure mode of test model

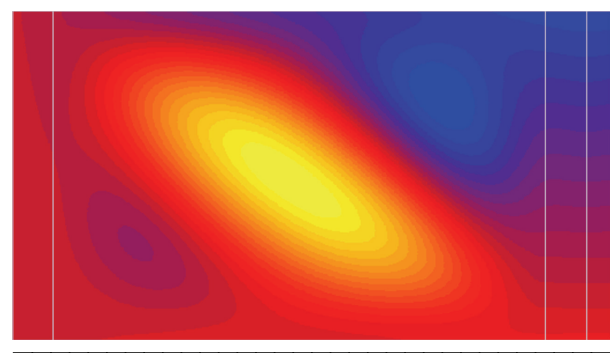

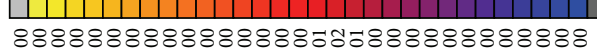
ภัก้

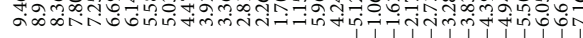

(iii) Out-of-plane displacement contour with $H / 500$

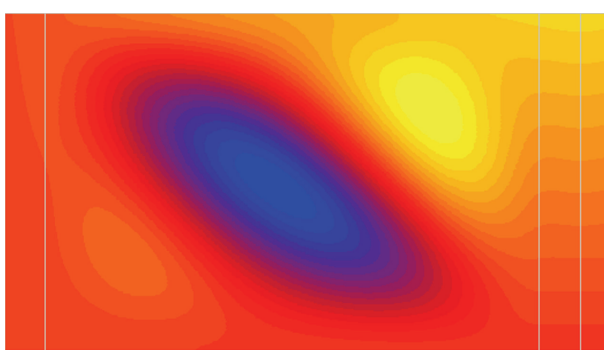
८888888888500088888888888888885 foñ

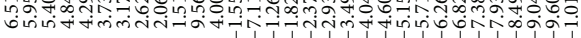

(ii) Out-of-plane displacement contour without imperfection
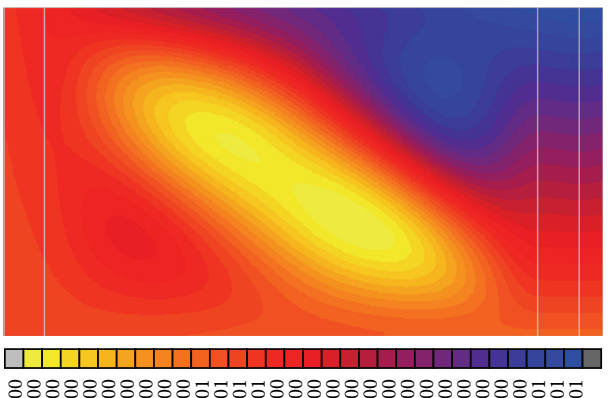

8888888888505088888888888888500

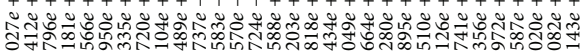

(iv)

(iv) Out-of-plane displacement contour with $H / 100$

(a) Ch00T6 specimen

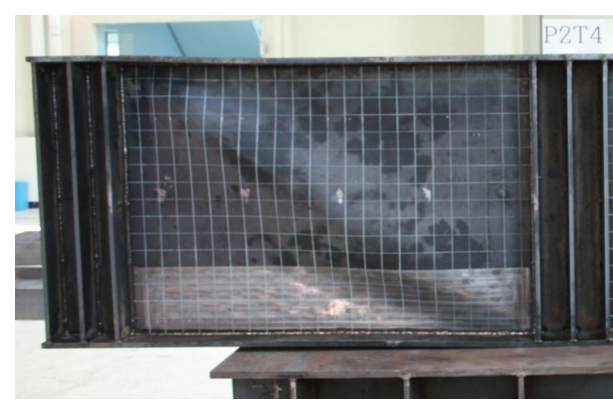

(i) Failure mode of test model



$\frac{2000505050508888888885058888888}{110}$

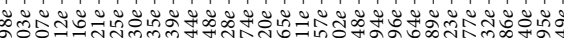
نi-i-i-7

(iii) Out-of-plane displacement contour with $H / 500$

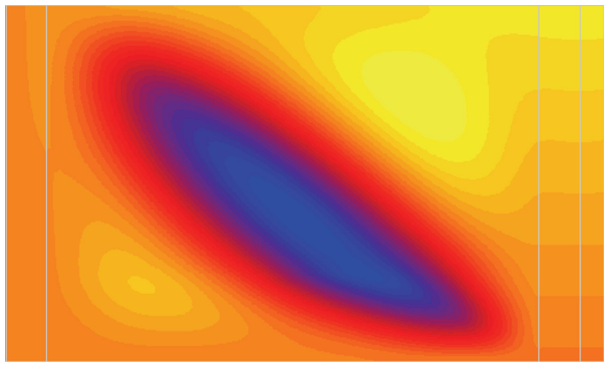

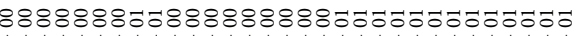

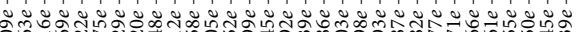

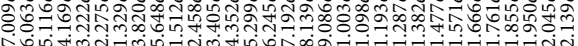

(ii) Out-of-plane displacement contour without imperfection

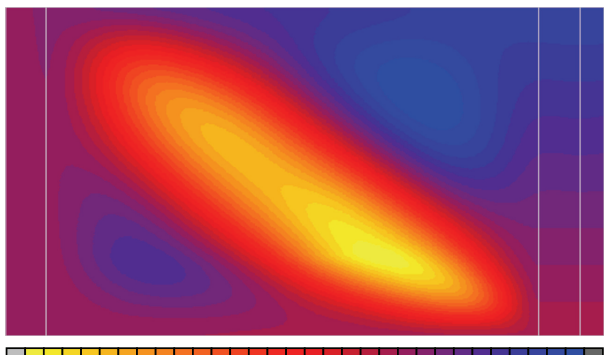

б.05050508888888888850888888888 O

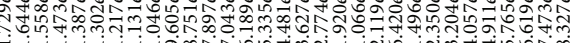

(iv) Out-of-plane displacement contour with $H / 100$

(b) Ch20T4 specimen

FIGURE 5: Failure mode comparisons of shear buckling test specimens depending on imperfection. 
TABLE 3: Shear buckling resistance of a web plate with imperfection $(\mathrm{kN})$.

\begin{tabular}{|c|c|c|c|c|c|c|}
\hline \multirow[b]{2}{*}{ Height (mm) } & \multicolumn{2}{|c|}{ Web corroded condition } & \multicolumn{4}{|c|}{ Imperfection (initial eccentric deformation) } \\
\hline & Corroded thickness (mm) & Corroded volume (\%) & 0 & $H / 100000$ & $H / 500$ & $H / 100$ \\
\hline \multirow{7}{*}{100} & 0 & 0 & 1160.0 & 1160.0 & 1160.0 & 1140.0 \\
\hline & 1 & 2.08 & 1160.0 & 1160.0 & 1160.0 & 1140.0 \\
\hline & 2 & 4.17 & 1140.0 & 1140.0 & 1140.0 & 1120 \\
\hline & 3 & 6.25 & 1100.0 & 1100.0 & 1100.0 & 1080.0 \\
\hline & 4 & 8.33 & 1060.1 & 1060.1 & 1060.1 & 1039.9 \\
\hline & 5 & 10.42 & 1020.0 & 1020.0 & 1020.0 & 1000.0 \\
\hline & 6 & 12.50 & 959.9 & 959.9 & 959.9 & 940.0 \\
\hline \multirow{7}{*}{200} & 0 & 0 & 1160.0 & 1160.0 & 1160.0 & 1140.0 \\
\hline & 1 & 2.08 & 1160.0 & 1160.0 & 1160.0 & 1140.0 \\
\hline & 2 & 4.17 & 1119.9 & 1119.9 & 1119.9 & 1100.0 \\
\hline & 3 & 6.25 & 1039.9 & 1039.9 & 1039.9 & 1020.0 \\
\hline & 4 & 8.33 & 959.9 & 959.9 & 959.9 & 940.0 \\
\hline & 5 & 10.42 & 920.0 & 920.0 & 920.0 & 900.1 \\
\hline & 6 & 12.50 & 779.9 & 779.9 & 779.9 & 779.9 \\
\hline
\end{tabular}

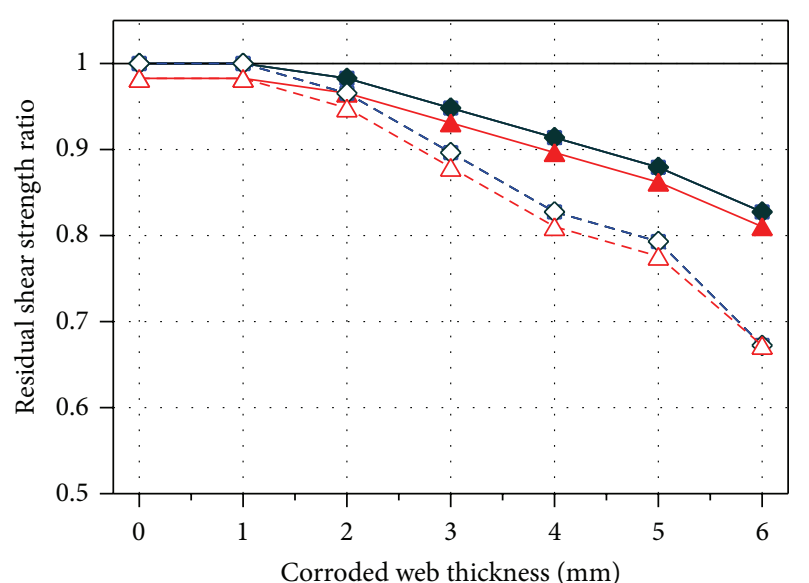

Simple supported model

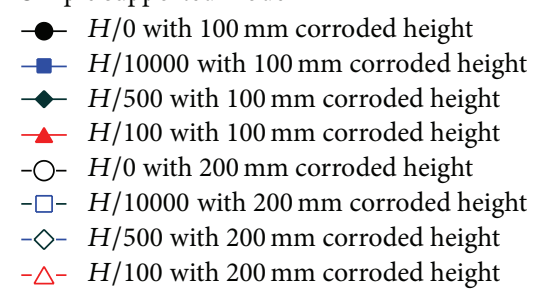

(a) Sectional damaged web plate thickness

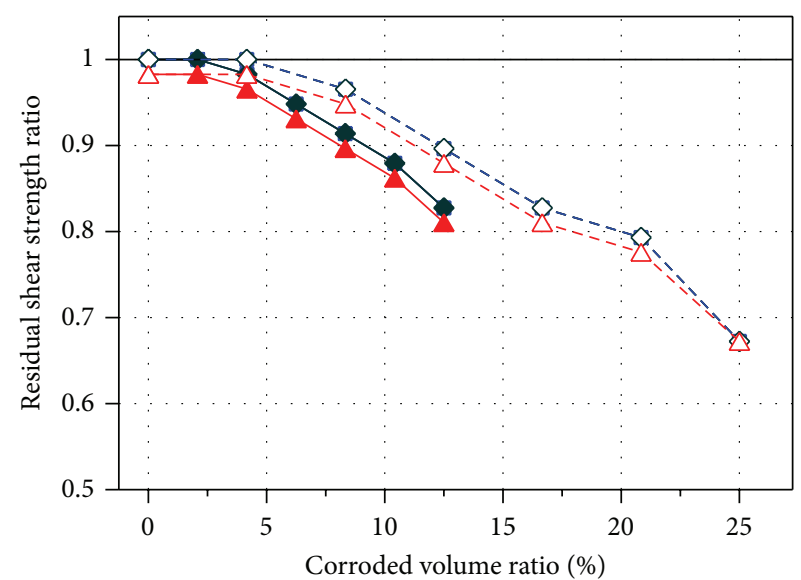

Simple supported model

- $\mathrm{H} / 0$ with $100 \mathrm{~mm}$ corroded height

$\rightarrow H / 10000$ with $100 \mathrm{~mm}$ corroded height

$\multimap-H / 500$ with $100 \mathrm{~mm}$ corroded height

- H/100 with $100 \mathrm{~mm}$ corroded height

-O- H/0 with $200 \mathrm{~mm}$ corroded height

- $\square-H / 10000$ with $200 \mathrm{~mm}$ corroded height

$-\diamond-H / 500$ with $200 \mathrm{~mm}$ corroded height

$-\triangle^{-} H / 100$ with $200 \mathrm{~mm}$ corroded height

(b) Sectional damaged volume

FIGURE 6: Shear buckling resistance ratios with roller support.

the boundary conditions, as shown in Table 4 and Figure 7. The shear buckling strengths steadily decreased at the same level as those of the simply supported cases. Thus, it was determined that boundary condition effect is not related to the relationship between imperfection and shear buckling strength of a web panel with sectional damage.

3.1.3. Relationship between Imperfection and Aspect Ratio Condition. In this study, an $800 \times 1200 \mathrm{~mm}$ web plate was used, because the FE model was based on the shear loading test specimen. Three aspect ratios were considered as analysis parameters to examine the relationship between imperfections and shear buckling strength, as the aspect ratio can be related to the web resistant properties for the shear loading condition. The effects of the aspect ratios were compared to the values of each analysis condition for corrosion level and corrosion height. Table 5 and Figure 8 summarize the FE analysis results. In web panels with an aspect ratio of 
TABLE 4: Shear buckling resistance of web plate with imperfection at hinge boundary $(\mathrm{kN})$.

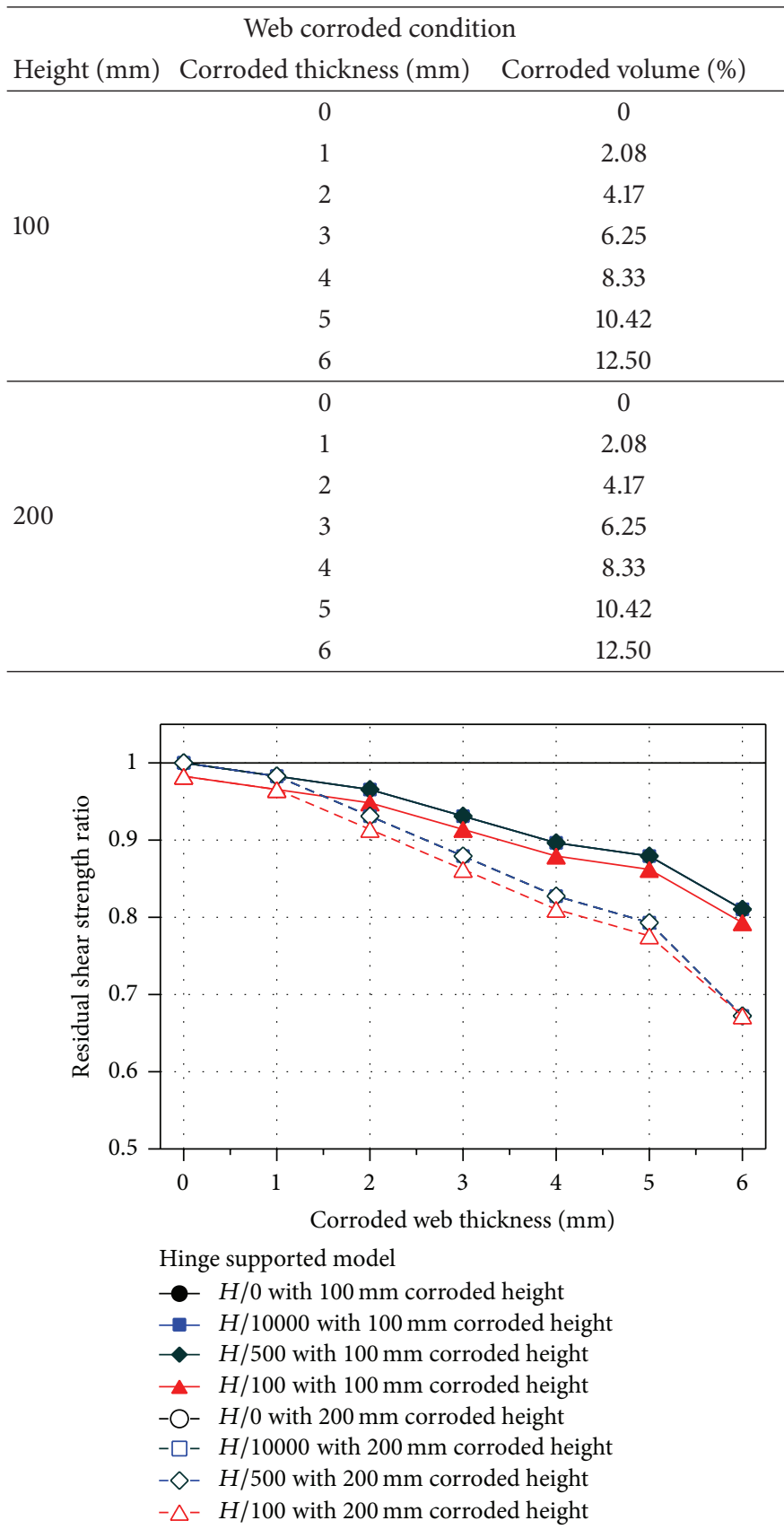

(a) Sectional damaged web plate thickness

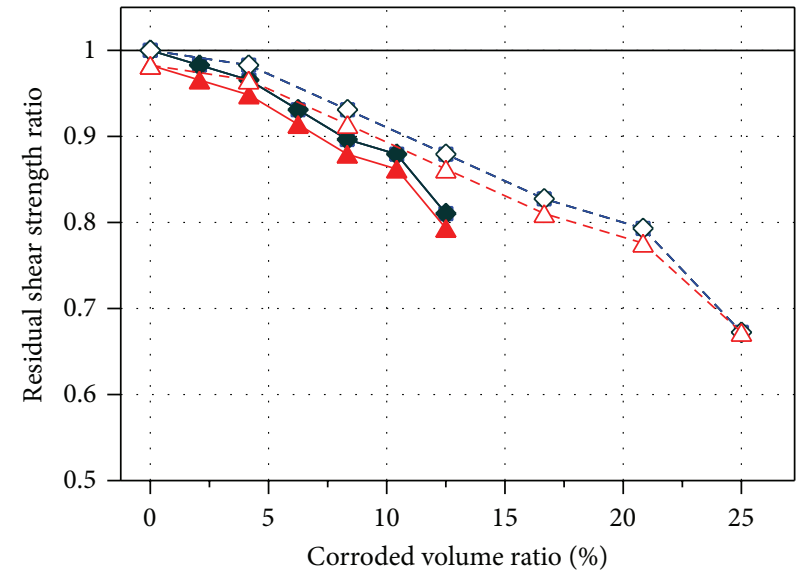

Hinge supported model

- $H / 0$ with $100 \mathrm{~mm}$ corroded height

$\rightarrow H / 10000$ with $100 \mathrm{~mm}$ corroded height

- $H / 500$ with $100 \mathrm{~mm}$ corroded height

- H/100 with $100 \mathrm{~mm}$ corroded height

-O- $\mathrm{H} / 0$ with $200 \mathrm{~mm}$ corroded height

- $\square-H / 10000$ with $200 \mathrm{~mm}$ corroded height

$-\diamond-H / 500$ with $200 \mathrm{~mm}$ corroded height

${ }_{-}^{-} H / 100$ with $200 \mathrm{~mm}$ corroded height

(b) Sectional damaged volume

FIGURE 7: Shear buckling resistance ratios with hinge support.

1.0, the shear buckling strength steadily decreased to $79 \%$ of the shear buckling strength of web panels without corrosion. For a 1.25 aspect ratio, the strength decreased to $73 \%$ of the shear buckling strength of web panels without sectional damage caused by corrosion. For a 1.50 aspect ratio, the strength decreased to $67 \%$ of the shear buckling strength of web panels without sectional damage. The changes in the shear buckling strengths presented similar tendencies to the other cases and previous study [4], and they showed a relatively significantly greater change with a higher aspect ratio web panel. Although their web aspect ratio was changed, the values of the web plate with the $H / 100$ eccentric deformation were also affected by approximately $2 \%$ compared to those without eccentric deformation, like in the other analysis cases. Therefore, it is thought that the aspect ratio of a web plate is not related to the relationship between imperfection and shear buckling strength of a web panel with corrosion. 

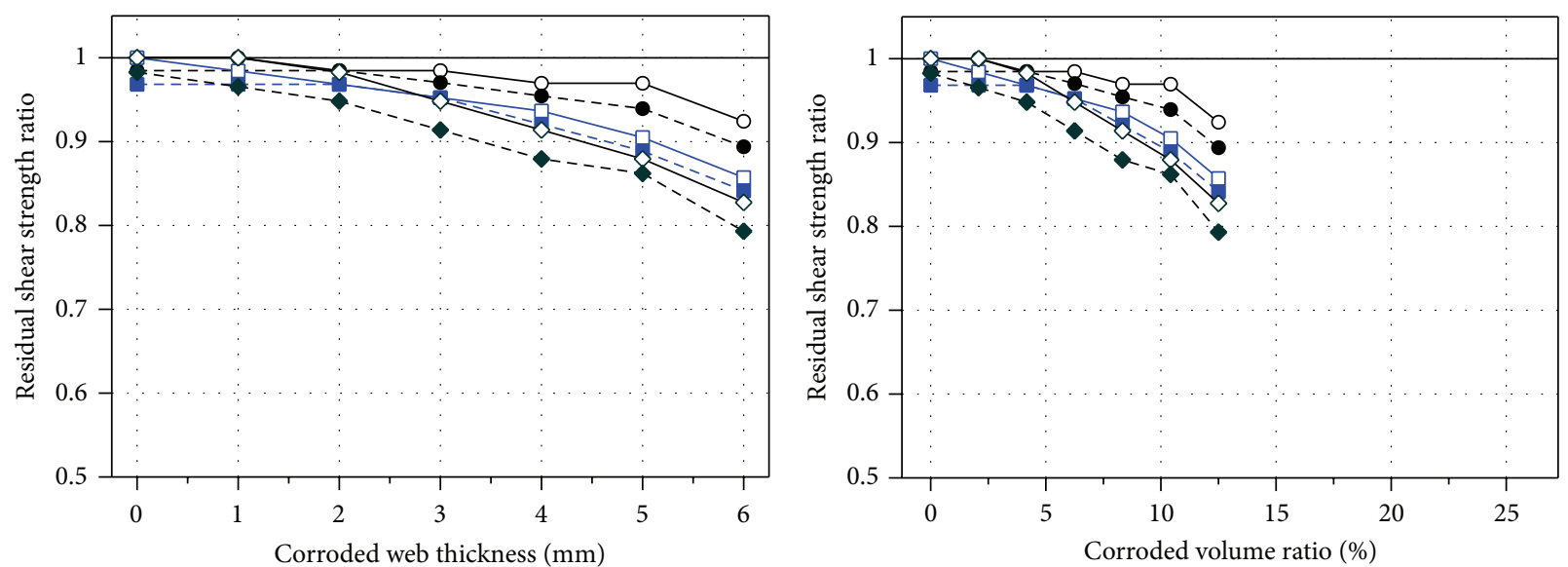

Aspect ratio with $100 \mathrm{~mm}$ corroded height model

$-0-H / 0$ with 1.00 aspect ratio

- $-H / 100$ with 1.00 aspect ratio

$\rightarrow-H / 0$ with 1.25 aspect ratio

- $H / 100$ with 1.25 aspect ratio

$\checkmark \quad H / 0$ with 1.50 aspect ratio

- $-H / 100$ with 1.50 aspect ratio

(a) Sectional damaged web plate thickness (100 $\mathrm{mm}$ corrosion height)

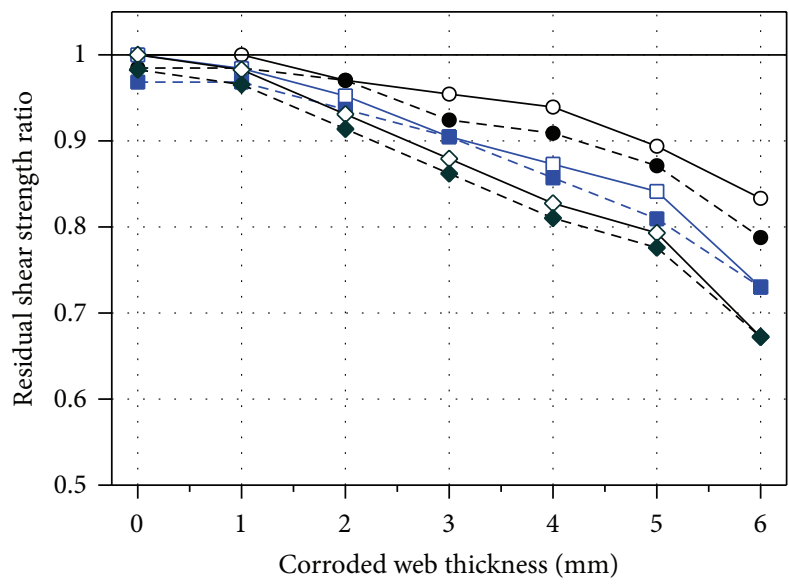

Aspect ratio with $200 \mathrm{~mm}$ corroded height model

-o- $H / 0$ with 1.00 aspect ratio

- $-H / 100$ with 1.00 aspect ratio

$\rightarrow-H / 0$ with 1.25 aspect ratio

- $H / 100$ with 1.25 aspect ratio

$\checkmark H / 0$ with 1.50 aspect ratio

- $-H / 100$ with 1.50 aspect ratio

(c) Sectional damaged web plate thickness (200 $\mathrm{mm}$ corrosion height)

Aspect ratio with $100 \mathrm{~mm}$ corroded height model

$-\mathrm{O}-\mathrm{H} / 0$ with 1.00 aspect ratio

- - H/100 with 1.00 aspect ratio

$\rightarrow-H / 0$ with 1.25 aspect ratio

- $\mathrm{H} / 100$ with 1.25 aspect ratio

$\checkmark \quad H / 0$ with 1.50 aspect ratio

- $H / 100$ with 1.50 aspect ratio

(b) Sectional damaged volume (100 $\mathrm{mm}$ corrosion height)

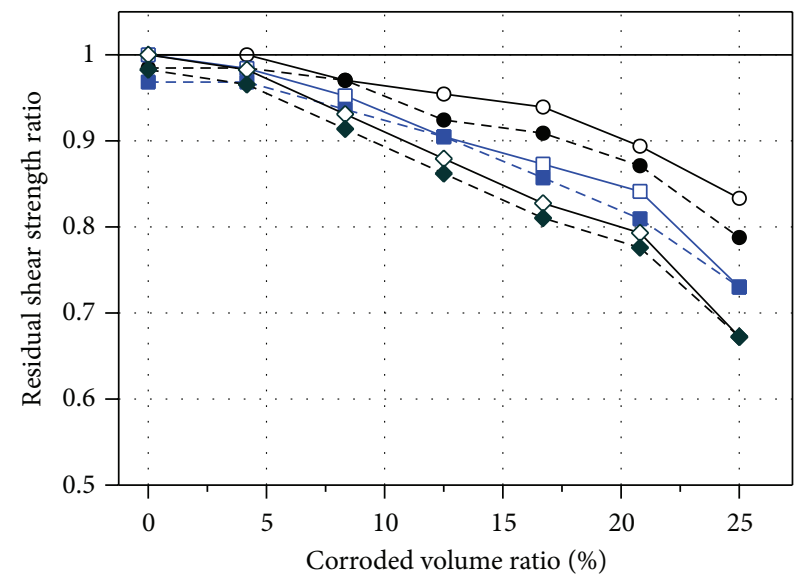

Aspect ratio with $200 \mathrm{~mm}$ corroded height model

-O- $\mathrm{H} / 0$ with 1.00 aspect ratio

- - $H / 100$ with 1.00 aspect ratio

$\rightarrow-H / 0$ with 1.25 aspect ratio

- $H / 100$ with 1.25 aspect ratio

$\diamond \mathrm{H} / 0$ with 1.50 aspect ratio

- - H/100 with 1.50 aspect ratio

(d) Sectional damaged volume (100 mm corrosion height)

FIGURE 8: Shear buckling resistance ratios depending on aspect ratio.

\subsection{Expanded Equation for Shear Buckling Resistance Factor}

3.2.1. Expanded Shear Buckling Resistance Factor Equations. In a web plate with sectional damage caused by corrosion, it is difficult to determine the shear resistant coefficient for calculating the design strength of the web plate according to design specifications since it has local sectional loss caused by corrosion, and its sectional loss is difficult to measure due to its irregular surface. Thus, a simple estimation method is needed to determine the sectional loss of a web plate with corrosion. In previous studies [4], the change in the shear buckling strength was assessed from a parametric study, and the residual shear resistant equation was suggested based on the corroded volume of the web section, using its reduction factor to easily estimate shear buckling resistance. As mentioned before in this study, it was evaluated that the initial eccentric deformation of a web plate with corrosion has a relatively small effect on the reduced shear buckling performance of the web. Shear buckling strengths of web panels with corrosion were shown to steadily decrease, depending 
TABLE 5: Shear buckling resistance of a web plate with imperfection depending on aspect ratio $(\mathrm{kN})$.

\begin{tabular}{|c|c|c|c|c|c|}
\hline \multirow[b]{2}{*}{ Aspect ratio } & \multicolumn{2}{|c|}{ Web damaged condition } & \multirow[b]{2}{*}{ Corroded volume (\%) } & \multicolumn{2}{|c|}{$\begin{array}{c}\text { Imperfection (initial eccentric } \\
\text { deformation) }\end{array}$} \\
\hline & Height $(\mathrm{mm})$ & Corroded thickness (mm) & & 0 & $H / 100$ \\
\hline \multirow{7}{*}{1.0} & \multirow{7}{*}{100} & 0 & 0 & 1320.1 & 1299.9 \\
\hline & & 1 & 2.08 & 1320.1 & 1299.9 \\
\hline & & 2 & 4.17 & 1299.9 & 1299.9 \\
\hline & & 3 & 6.25 & 1299.9 & 1281.0 \\
\hline & & 4 & 8.33 & 1280.0 & 1260.0 \\
\hline & & 5 & 10.42 & 1280.0 & 1240.1 \\
\hline & & 6 & 12.50 & 1220.1 & 1180.0 \\
\hline \multirow{7}{*}{1.0} & \multirow{7}{*}{200} & 0 & 0 & 1320.1 & 1299.9 \\
\hline & & 1 & 2.08 & 1320.1 & 1299.9 \\
\hline & & 2 & 4.17 & 1281.0 & 1281.0 \\
\hline & & 3 & 6.25 & 1260.0 & 1220.1 \\
\hline & & 4 & 8.33 & 1240.1 & 1199.9 \\
\hline & & 5 & 10.42 & 1180.0 & 1150.0 \\
\hline & & 6 & 12.50 & 1100.0 & 1039.9 \\
\hline \multirow{7}{*}{1.25} & \multirow{7}{*}{100} & 0 & 0 & 1260.0 & 1220.1 \\
\hline & & 1 & 2.08 & 1240.1 & 1220.1 \\
\hline & & 2 & 4.17 & 1220.1 & 1220.1 \\
\hline & & 3 & 6.25 & 1199.9 & 1199.9 \\
\hline & & 4 & 8.33 & 1180.0 & 1160.0 \\
\hline & & 5 & 10.42 & 1140.1 & 1119.9 \\
\hline & & 6 & 12.50 & 1080.0 & 1060.1 \\
\hline \multirow{7}{*}{1.25} & \multirow{7}{*}{200} & 0 & 0 & 1260.0 & 1220.1 \\
\hline & & 1 & 2.08 & 1240.1 & 1220.1 \\
\hline & & 2 & 4.17 & 1199.9 & 1180.0 \\
\hline & & 3 & 6.25 & 1140.1 & 1140.1 \\
\hline & & 4 & 8.33 & 1100.0 & 1080.0 \\
\hline & & 5 & 10.42 & 1060.1 & 1020.0 \\
\hline & & 6 & 12.50 & 920.0 & 920.0 \\
\hline \multirow{7}{*}{1.50} & \multirow{7}{*}{100} & 0 & 0 & 1160.0 & 1140.0 \\
\hline & & 1 & 2.08 & 1140.0 & 1120.0 \\
\hline & & 2 & 4.17 & 1120.0 & 1100.0 \\
\hline & & 3 & 6.25 & 1080.0 & 1060.1 \\
\hline & & 4 & 8.33 & 1039.9 & 1020.0 \\
\hline & & 5 & 10.42 & 1020.0 & 1000.0 \\
\hline & & 6 & 12.50 & 940.0 & 920.0 \\
\hline \multirow{7}{*}{1.50} & \multirow{7}{*}{200} & 0 & 0 & 1160.0 & 1140.0 \\
\hline & & 1 & 2.08 & 1140.0 & 1120.0 \\
\hline & & 2 & 4.17 & 1080.0 & 1060.1 \\
\hline & & 3 & 6.25 & 1020.0 & 1000.0 \\
\hline & & 4 & 8.33 & 959.9 & 940.0 \\
\hline & & 5 & 10.42 & 920.0 & 900.1 \\
\hline & & 6 & 12.50 & 779.9 & 779.9 \\
\hline
\end{tabular}


on web corrosion conditions, regardless of geometrical and boundary conditions. The decreased shear buckling strength tendency could be explained by volume loss caused by corrosion. Thus, FE analysis results were combined with FE analysis results of a previous study to expand the shear buckling resistance factor equation, including the effect of imperfections in a web plate on its shear strength. To expand the shear buckling strength relationship, the web volume ratio $\left(C_{v}\right)$ and the shear strength reduction factor $\left(\mathrm{RS}_{\mathrm{f}}\right)$ are defined in (1) as in the previous study:

$$
\begin{aligned}
C_{v} & =\frac{C_{c}}{C_{s}} \\
\mathrm{RS}_{\mathrm{f}} & =\frac{U_{c}}{U_{s}},
\end{aligned}
$$

where $C_{s}$ is the total volume of the web, $C_{c}$ is the sectional damage volume of the web plate, $U_{s}$ is the shear buckling strength of the web without sectional damage, and $U_{c}$ is the shear buckling strength of the web with sectional damage caused by corrosion.

From the FE analyses of a web plate without an initial eccentric deformation, its shear buckling reduction factor equation was derived as (2), using the damaged web volume ratio (sectional damaged volume ratio, $C_{v}$ ). From the FE analysis data in this study, the shear buckling reduction factor equation was suggested as (3). Equation (3), derived by the FE analysis results with an initial eccentric deformation, shows a slightly different distributed shape compared to the distributions of the FE analysis results of the previous study. However, some FE analysis data of the previous study showed some differences when compared to (3) derived from the FE analysis data of this study. In addition, almost all of the FE analysis results with an initial eccentric deformation were within the $95 \%$ prediction band derived from the regression curve in the previous study as the initial eccentric deformation effect on the shear buckling strength is not high. As shown in Figure 9, in the case of low sectional damage caused from corrosion, the variation of the reduction in the shear buckling resistance had little effect on the sectional damage. In the case of higher sectional damage caused from corrosion, however, its variation in the same corrosion was greatly apparent. If corrosion volume was used as a performance parameter and not a structural sectional parameter, as in this study and the previous study, it could be necessary to evaluate more conservatively by including various damage conditions and imperfections. In the case of the lower boundary, its $95 \%$ prediction band, derived in the previous study using (4), was satisfied conservatively, except for some results. Therefore, (4) can be used to conservatively evaluate the shear buckling reduction factor of a web plate with corrosion when unable to estimate the exact section damage caused by corrosion:

$$
\begin{aligned}
\mathrm{RS}_{\mathrm{f}} & =0.7368+\frac{0.2859}{1+e^{-\left(\left(C_{v}-8.8318\right) /-3.4666\right)}} \\
\mathrm{RS}_{\mathrm{f}} & =-0.5806+\frac{1.8005}{1+e^{-\left(\left(C_{v}-47.4707\right) /-24.1883\right)}} \\
\mathrm{RS}_{\mathrm{f}} & =0.6246+\frac{0.2997}{1+e^{-\left(\left(C_{v}-8.9931\right) /-3.6791\right)}} .
\end{aligned}
$$

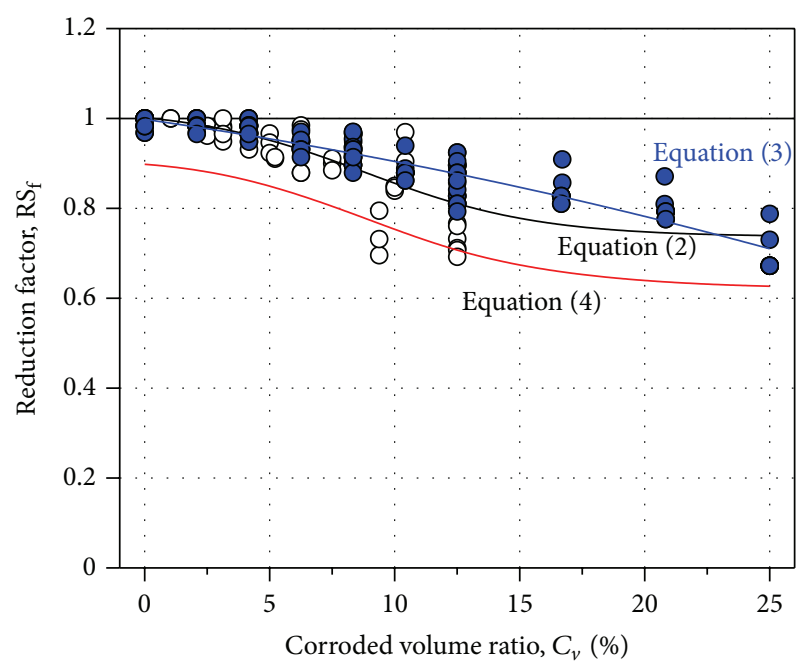

Shear buckling reduction ratio

$O \quad F E$ analysis results without imperfection

- FE analysis results with imperfection

— Regression curves of previous study

- Regression curves of this study 95\% prediction of previous study

_ Line/scatter plot 33

FIGURE 9: Shear buckling reduction factor equation.

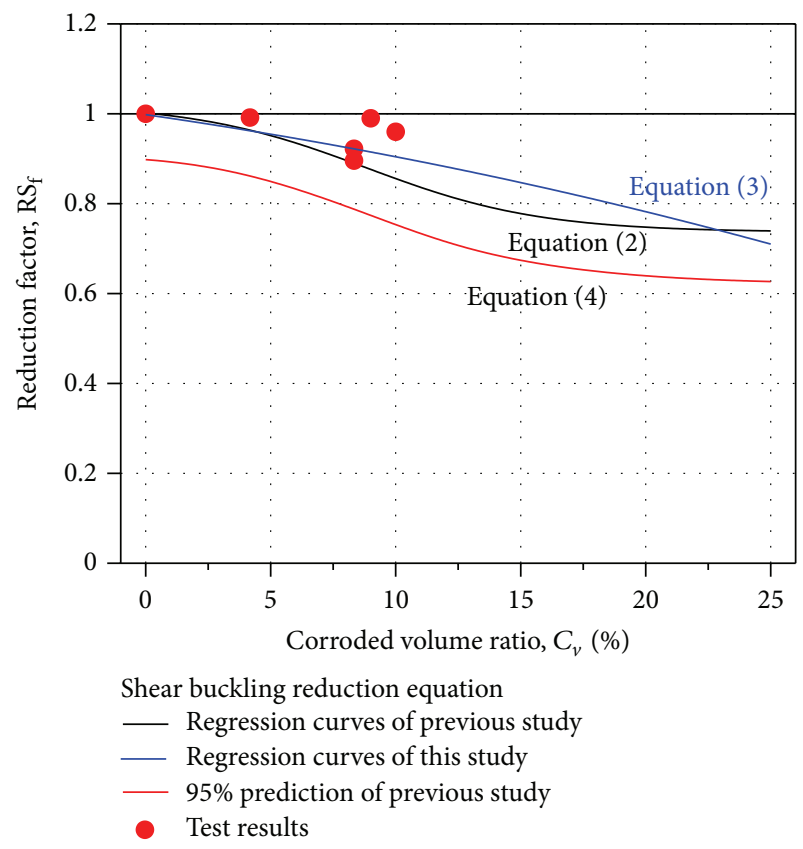

FIGURE 10: Comparison of test results with suggested shear buckling equation.

3.2.2. Example for Calculation of Shear Buckling Resistance of a Web Plate with Sectional Damage. To verify the expanded shear buckling reduction factor for maintenance and inspection of web panels, the sectional damage of the web plate used in shear loading tests was calculated and compared to the suggested shear buckling resistance equations $[3,12]$. Figure 10 shows the comparison between the suggested shear 
buckling resistance equations and the test results. As shown in the figure, the test results are similar to (2) and (3) for relatively little sectional damage of the web plate. For shear loading tests, sectional damage was exactly calculated; thus, the shear buckling strengths were very similar to the values calculated using (2) and (3). However, it is difficult to calculate exact sectional damage caused by corrosion in the field. Therefore, (4) can be used to conservatively estimate the shear buckling strength for a web plate when the exact amount of sectional loss due to corrosion is unknown, such as in the field.

\section{Conclusions}

This study carried out a series of a nonlinear finite element (FE) analyses of a web plate pane to examine the relationship between imperfections and shear buckling resistance of a web plate with sectional damage caused by corrosion. To examine the imperfection effect on the shear buckling resistance of a web plate with sectional damage, an initial out-of-plane deformation was considered as a main parameter, and the shear buckling resistance of the sectional damaged web plate was examined based on aspect ratio, boundary condition, and the sectional damaged height of the web plate from the lower flange.

The shear buckling resistance of a sectional damaged web panel with $H / 100,000$ and $H / 500$ imperfections was shown to be similar to that of a web plate without imperfections. However, for web panels with an $H / 100$ imperfection, their shear resistance values decreased to approximately $2 \%$ of those of the web plate without sectional damage. In terms of sectional web damage thickness, the shear resistance values decreased according to the sectional damage web height from the lower flange, but they were also shown to significantly decrease in the web panel that had a lower sectional damage web height compared to the sectional damage volume ratio. For the sectional damaged web plate with different aspect ratios, their resistance to change exhibited a similar tendency, and it markedly changed in the higher aspect ratio web. The equation for shear buckling resistance of a web plate with sectional damage was modified based on a comparison of the previous study results for use in the practical maintenance of corrosion damaged web plates.

\section{Competing Interests}

The authors declare that there is no conflict of interests regarding the publication of this paper.

\section{Acknowledgments}

This research was supported by Development of Hybrid Substructure System for Offshore Wind Farm, Project no. 20123010020110 funded by the Ministry of Trade, Industry and Energy, Korea.

\section{References}

[1] J. R. Kayser and A. S. Nowak, "Reliability of corroded steel girder bridges," Structural Safety, vol. 6, no. 1, pp. 53-63, 1989.
[2] J.-H. Ahn, S. Kainuma, F. Yasuo, and I. Takehiro, "Repair method and residual bearing strength evaluation of a locally corroded plate girder at support," Engineering Failure Analysis, vol. 33, pp. 398-418, 2013.

[3] I.-T. Kim, M.-J. Lee, J.-H. Ahn, and S. Kainuma, "Experimental evaluation of shear buckling behaviors and strength of locally corroded web," Journal of Constructional Steel Research, vol. 83, pp. 75-89, 2013.

[4] J.-H. Ahn, I.-T. Kim, S. Kainuma, and M.-J. Lee, "Residual shear strength of steel plate girder due to web local corrosion," Journal of Constructional Steel Research, vol. 89, pp. 198-212, 2013.

[5] J.-H. Ahn, S. Kainuma, and I.-T. Kim, "Shear failure behaviors of a web panel with local corrosion depending on web boundary conditions," Thin-Walled Structures, vol. 73, pp. 302-317, 2013.

[6] J. K. Paik, J. M. Lee, and M. J. Ko, "Ultimate shear strength of plate elements with pit corrosion wastage," Thin-Walled Structures, vol. 42, no. 8, pp. 1161-1176, 2004.

[7] D. Ok, Y. Pu, and A. Incecik, "Computation of ultimate strength of locally corroded unstiffened plates under uniaxial compression," Marine Structures, vol. 20, no. 1-2, pp. 100-114, 2007.

[8] J. E. Silva, Y. Garbatov, and C. Guedes Soares, "Ultimate strength assessment of rectangular steel plates subjected to a random localised corrosion degradation," Engineering Structures, vol. 52, pp. 295-305, 2013.

[9] J. Huh, I.-T. Kim, and J.-H. Ahn, "Locally corroded stiffener effect on shear buckling behaviors of web panel in the plate girder," Advances in Materials Science and Engineering, vol. 2015, Article ID 586264, 19 pages, 2015.

[10] National Institute for Land and Infrastructure Management, "Research on local corrosion of highway steel bridges," Technical Note 294, National Institute for Land and Infrastructure Management, 2006 (Japanese).

[11] J. Murakoshi and Y. Tanaka, "Research on retrofitting for corroded steel girder around expansion joint," Civil Engineering Research Reports, CAESAR, 2008.

[12] J.-H. Ahn, J.-H. Cheung, W.-H. Lee, H. Oh, and I.-T. Kim, "Shear buckling experiments of web panel with pitting and through-thickness corrosion damage," Journal of Constructional Steel Research, vol. 115, pp. 290-302, 2015.

[13] T. E. Dunbar, N. Pegg, F. Taheri, and L. Jiang, "A computational investigation of the effects of localized corrosion on plates and stiffened panels," Marine Structures, vol. 17, no. 5, pp. 385-402, 2004.

[14] M. F. Hassanein, "Imperfection analysis of austenitic stainless steel plate girders failing by shear," Engineering Structures, vol. 32, no. 3, pp. 704-713, 2010.

[15] AASHTO/AWS, "Bridge welding code," Tech. Rep. ANSI/ AASHTO/AWS D1.5M/D1.5:2002, A Joint Publication of American Association of State Highway and Transportation Officials, Washington, DC, USA; American Welding Society, Miami, Fla, USA, 2002.

[16] Marc 2012 User’s Guide, MSC Software Corporation, 2012. 

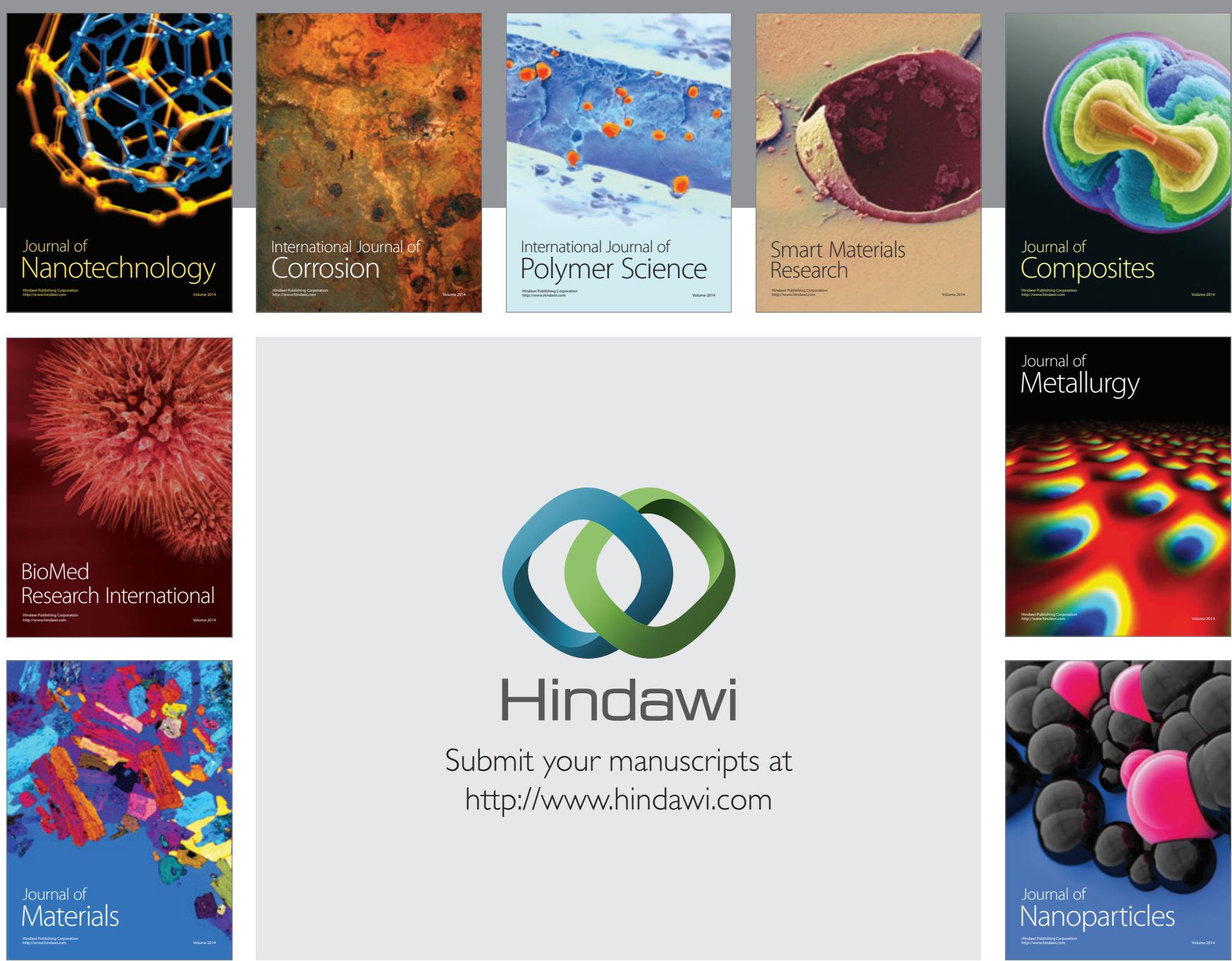

\section{Hindawi}

Submit your manuscripts at

http://www.hindawi.com

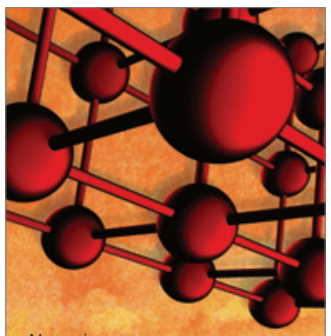

Materials Science and Engineering
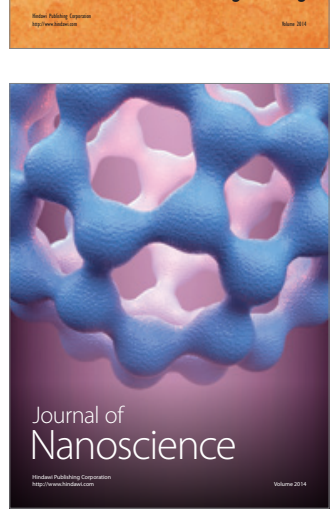
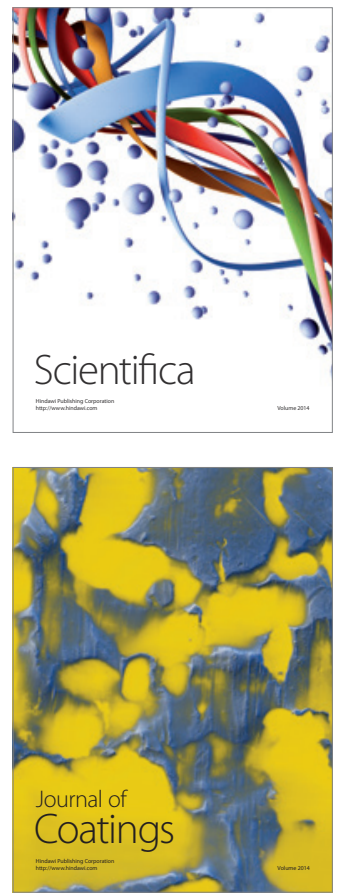
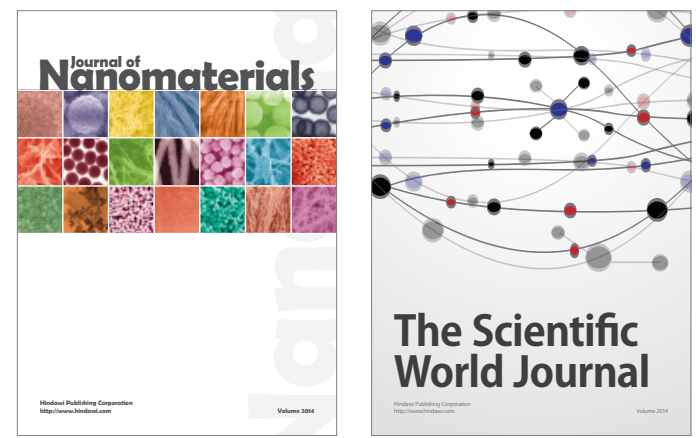

The Scientific World Journal
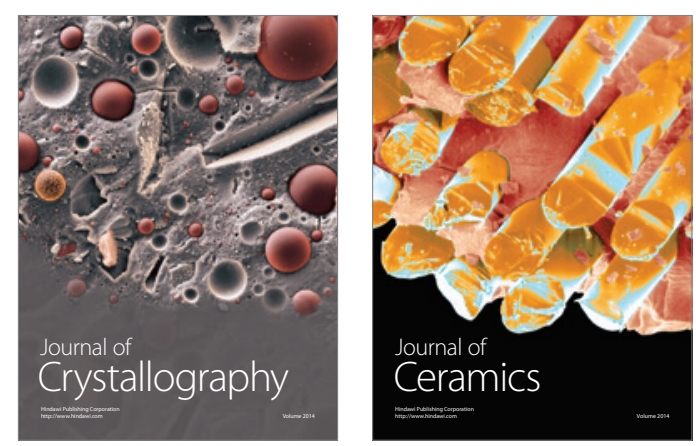
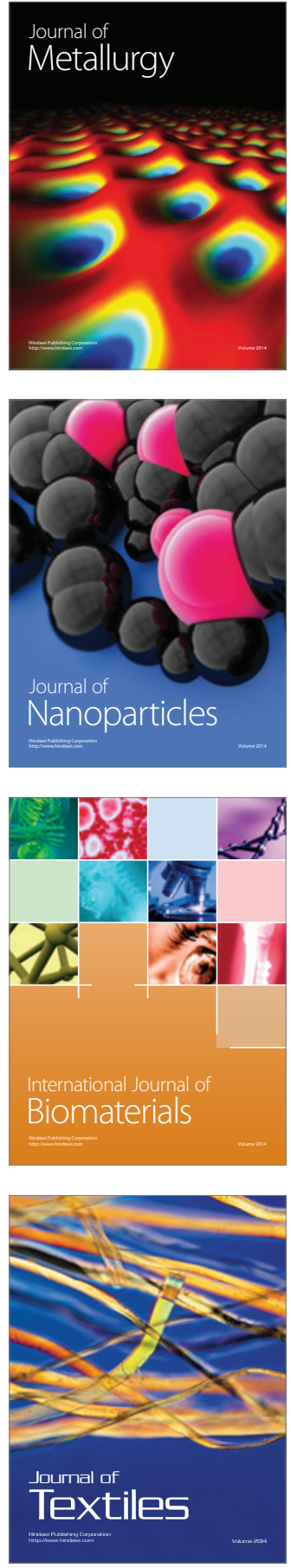